\title{
Effectiveness of Voluntary Counseelling and Testing in the Fight against HIVIAIDS among the Youth: A Case Study of Thika District
}

\author{
Anne Muiru \\ School of Education, Mount Kenya University \\ annemuiru12@gmail.com
}

\section{Doi:10.5901/mjss.2014.v5n5p}

\section{Abstract}

Despite many initiatives to combat HIVIAIDS many youth continue to die and the number of orphans continue to increase. The old are taking care of the youth while in reality they are the ones who should be taken care of. The youth perceive themselves at no risk of HIVIAIDS. They believe that they will not be harmed; they do not imagine that they will come into contact with someone infected with the virus. They view HIVIAIDS as someone else disease like of the gay men and drug users. It is unfortunate that very few youth seek VCT services. This study then is timely as it seeks to find out why the youth do not visit the VCT centers, how effective are the current VCT centers and what needs to be done to make them more effective.

Keywords: Youth, HIV/AIDS, Counslling, Orphans

\section{Back Ground Information}

In recent years, the burden of HIVIAIDS has persistently proved to be a major challenge to humanity. Resource center has documented that more than 40 million adults worldwide are now living with HIVIAIDS. The number of children infected with HIVIAIDS stands at 1.3million while 5.3 million people were infected cases in 2001 alone. In the same year, the global HIVIAIDS related deaths reached a record 3 million (UNAIDS 2001).

In Africa South of Sahara, over 28 million adults are infected while 1.5 million have already died of HIVIAIDS (UNAIDS 2001). Owing to the increasing level of poverty in Africa, the management of HIVIAIDS has become extremely difficult as most of the victims can hardly afford anti-retroviral drugs.

In Kenya over 3 million people mainly in the age brackets $15-49$ years are infected. On average every district in Kenya carry a fair share of the burden with over $20 \%$ of adults being infected. On average 700 people are dying every day(FHI 2001) in Kenya with the spread cutting through all walks of life and status.

HIVIAIDS has led to a drastic reduction in the tax base. Insecurity has increased as more security forces die of the dreaded disease. The education sector in particular has in the recent past been suffering from a reduced enrolment and rising dropout rate of children since as orphans they can hardly solicit sustainable support for their fees. The teachers in the private and public institutions have also been affected. An average of 15 teachers dies every day (FHI 2002). In a nutshell, every sector of this country is affected in different ways. More energetic and productive labour force has died or lives on lives on a low per capita income.

Voluntary counseling and testing has as a result been found to be an essential component of an effective response to the HIVIAIDS pandemic. VCT is a process by which out of ones own volition, finds out whether or not he is infected with HIV the virus that causes AIDS. VCT can help them know that sex is not worthy dying for, to take precautions or face the consequences (UNAIDS 2001). Voluntary counseling and testing is the key to behavior change. Research conducted WHO is Uganda and Zambia (2001) show that people who know their HIVIAIDS status whether negative or positive drastically change their behavior.

A VCT efficacy study in Kenya, Trinidad and Tanzania compared the prevalence of unprotected sexual intercourse six months after intervention through HIVIAIDS counseling and testing and another group that was only given health information. The results showed that those who had been counseled and later tested had drastically changed their behavior (FHI 2000). A recent study on the effectiveness of VCT demonstrated a $40 \%$ reduction in the number of unprotected sexual acts among those who received VCT. (Sagima et al 1998:4).

Therefore as the saying goes that knowledge is power (UNAIDS 1999) VCT will help increase ones knowledge of his or her status. This is a powerful weapon in the national effort to fight the pandemic bearing in mind that majority of the youth do not know their HIV status. The Kenya Demographic Health Survey of 1998 showed that only 15\% of the youth 
knew of their HIVIAIDS status while about $67 \%$ indicated that they would like to have a HIV test.

\section{Problem Statement}

There are about 1.2 billion young people worldwide (UNFPA 2002). The 1999 Kenya census showed that youth in and out of school constitute more than $50 \%$ of the population. In regard to this study, the youth group will be taken to cover the age brackets of $18-24$ years as defined by the united Nations (WHO 1998). The youth hold enormous potential in the growth agenda of this country in terms of Health, Education, Agriculture and Technology and therefore it is important that their lives be saved from the HIVIAIDS pandemic. (UNFPA 2002) estimates that 11.8 million youth are currently living with HIVIAIDS.(UNFPA 2002) also estimates that 2.6 million young people contract the virus that carries the HIVIAIDS every year. Dr. Micheal Merson the current director of WHO global program on AIDS estimates that half of the worldwide infection since the beginning of the pandemic occurred among the youth aged 18-24 years.

A lot of effort has been put in the fight against HIVIAIDS in Kenya. The Kenya government declared it a national disaster in 1998. Institutions like WHO,FHI,UN, USAID have all come in with both material and financial support to carry out research and create more awareness confirming the HIVIAIDS is a real monster. There has also been increased advertisement in the print and electronic media. Seminars and conference have been held to discuss this big issue. The government and other non-governmental organizations have also used community based activities as well as roadside billboards continually to address the problem of HIVIAIDS among the youth. Millions of shillings have been spent in the constructions of VCT centers all over the country. There are about 117 VCT centers currently and the government aims at setting up more VCT centers about 350 or at least 5 VCT centers in every district. (NASCOP 2002).

Despite all these effort many youth continue to die and the number of orphans continue to increase. The old are taking care of the youth while in reality they are the ones who should be taken care of. The youth perceive themselves at no risk of HIVIAIDS. They believe that they will not be harmed; they do not imagine that they will come into contact with someone infected with the virus. They view HIVIAIDS as someone else disease like of the gay men and drug users.

Previous research has identified VCT as one of the national agenda in the prevention effort. At the consultative meeting on VCT by Kemri and University of Nairobi it was agreed that voluntary counseling and testing can enable the youth mitigate the impact of HIV in their lives and that of their friends and can increase awareness of the disease at a personal level. However it is unfortunate that very few youth seek VCT services. This study then is timely as it seeks to find out why the youth do not visit the VCT centers, how effective are the current VCT centers and what needs to be done to make them more effective.

\section{Theoretical framework}

A number of theories were used as a guide to this.

\subsection{The Health Belief Model}

This theory was first developed in the 1950s by social psychologist Godfrey Holhbaum, Irwin Rosen stock and Stephen Kegels working in the US public health services. In the 1970s Becker advanced it.

The Health Belief Model is one of the most widely used conceptual framework for understanding health behavior. Its process begins with the readiness to act, to do something in order to become physically well because he believes that he is susceptible to a serious illness. The readiness to act is experienced as a real and personal threat. The perceived threat of possible infection is accompanied by cues to action due to relatives and friends who have succumbed to the illness.

The HBM is based on the premise that people consciously and rationally evaluate the risk and then way the benefits and costs of various actions. This model is relevant to the youth in relation to HIVIAIDS because of the understanding that a person will take health related action if that person;

a. Feels that negative health condition can be avoided.

b. That the youth has positive expectations like by taking a recommended action, he or she will avoid a negative health conditions.

c. Believes that he can successfully take a recommended health action.

The HBM is very applicable to the youth in the sense that it serves as a framework for motivating people to take health actions with the desire to avoid negative health consequence as the prime motivations. HIVIAIDS is a negative health consequence and the desire to avoid HIV can be used to motivate sexually young people to go for VCT and 
practice safe sex.

Avoiding a negative health consequence is a key element of Health belief Model meaning that if the youth would take up HIV Aids as a personal responsibility then they can avoid being infected. The HBM is based on six concepts, which are very relevant to the youth in relation to HIVIAIDS.

a. Perceived susceptibility - where one believes that he has a chance of getting a particular condition like HIVIAIDS due to his risky behavior of having many sexual partners, alcohol etc.

b. Perceived severity - it is the belief of how serious the condition and the consequences of HIVIAIDS are. During the period when one is sick he suffers greatly and the youth have seen such people.

c. Perceived benefits -one belief that if he can take the desired action, he can reduce the risk of seriousness of the impact. This can help him define the action to take how, where and when.

d. Perceived barriers - these are ones beliefs in the tangible and psychological costs of the advised behavior, The youth can avoid the barriers like peer pressure and reduce those barriers by seeking assistance from a counselor.

e. Cues of action - these are strategies to activate "redness" like to promote awareness and provide new information. This can be done through the use of reminder messages like posters, announcements, billboards all advising on the need to know one status.

f. Self-efficacy - this is the confidence in one's ability to take actions, which can be provided through training, guidance and positive reinforcement like information about where to get tested. Based on the above, the youth can help fight against HIVIAIDS by being encouraged to set short term goals that are easy to achieve than long term goals that may not be realized in months or years.

\subsection{The Theory of Reasoned Action}

Azen Fishbein advocated this theory in 1980. It states that men act to achieve their intentions, purposes, aims, ends objectives and goals. In doing so, men will exercise will or judgement, they will choose, assesses and evaluates what they will do or are doing or have done. One will involve moral principles in arriving at decisions.

Ritzier (1983:326) says individual preferences are given and fixed that actors must select between alternative choices of action in pursuing these ends and their selection of a course of action will be rational.

The theory of reasoned action is very relevant to the youth in relation to HIVIAIDS in the sense that attitudes towards sexual behaviors and evaluations of those consequences. This theory emphasizes that if there is going to be change in the fight against HIVIAIDS then:

a. The youth have to be informed about how HIVIAIDS is transmitted and how this can be prevented.

b. The youth have to be motivated to reduce AIDS risks, which is influenced by social norms, believes and personal experiences with someone who has contracted HIVIAIDS.

c. There is need to improve the youth behavioral skills if AIDS risk is to be reduced and this include being able to communicate effectively and assertively with their partners as well as being able to utilize protective strategies and avoid higher risk practices.

d. Therefore if the youth can reason, know the consequences of HIVIAIDS then the risk of HIVIAIDS can be reduced.

\subsection{Aids Risk Reduction Model (A.R.R.M)}

Cantania, Kegels and Coates developed it in 1990. It provides a framework for explaining and predicting behavior change efforts of individuals in relationships to the sexual transmission of HIVIAIDS. The AIDS Risk Reduction Model has three stages that influence its success.

a. Recognition and labeling of ones behavior as high risk where one believes that he is susceptible to contracting HIV and one has a belief that having AIDS is undesirable.

b. Making a commitment to reduce high-risk sexual contacts and to increase low risk activities.

c. Taking action. This can be done through information seeking, obtaining remedies and enacting solutions from public education campaigns, informal support groups and VCTs. 


\section{Methodology}

\subsection{Site Description}

The study was conducted in Thika District within the central province of Kenya. Its headquarters are Thika municipality, which is East of Nairobi city.

According to the 1999 Kenya government population censes, the district had a total population of about 645,713 with 323,427 males and 322,234 females. The youth account for about $23 \%$ of the total population in the district. (Kenyan Government 1999 population Census). The District is made up of six geographical divisions namely Gatanga, Gatundu, Kakuzi, Kamwangi, Thika municipality and Ruiru. This district is also endowed with different economic and social activities. Many farmers engage in plantation agriculture, while others practice subsistence - farming business etc. Schools and tertiary colleges exist where the youth attend.

\subsection{Site Selection}

The researcher purposively selected Thika district since it is a cosmopolitan town with government offices, business premises, industrial Centre's and tertiary colleges. The influx of people from different parts of the country either in search of work, study or for business purposes has made the population to increase. It was therefore imperative to see how the youth, the focus of the study view HIVIAIDS and what steps they were taking to reduce it.

The district was also convenient to the researcher in terms of accessibility and financial constraints. The study concentrated on only three divisions namely Thika Municipality, Kakuzi and Ruiru. Kakuzi was also purposively selected since there were many youth working in the pineapple, coffee and flower plantations. It was important to see how the youth here view HIVIAIDS.

The researcher also got interested in carrying out research here as it had been noted by the HIVIAIDS survey in 2001 that this district had and increasing number of HIVIAIDS reported cases of about 31\% (population Council 2001). This drew the curiosity of the researcher to find out how the youth view HIVIAIDS and whether they were seeking VCT services.

\subsection{Units of Analysis}

The youth in this study were the unit of analysis. The youth were sexually active and vulnerable to HIVIAIDS hence it was necessary to understand how they perceived VCT centres. The study attempted to find out how the existing VCT centres were carrying out their services and how they could be made more effective to cater for the special needs of the youth.

\subsection{Sampling procedure}

The study combined simple random and non-probability sampling techniques so as to select a representative sample. The researcher purposively selected three divisions; Thika municipality, Kakuzi and Ruiru. The researcher selected 86 respondents (Youth 18- 24 years) from all the three divisions. 46 respondents were selected from Thika municipality to cater for the high population. 20 respondents were selected from Kakuzi while 20 respondents were selected from Ruiru. All the respondents were selected from the various VCT centers, tertiary colleges, churches, markets, industries and farmers all over the division to make the sample representative.

\section{Data collection Methods and Research instruments}

The study utilized primary, secondary and observation methods of data collection.

\subsection{Primary Data}

Primary data was both quantitative and qualitative, and the following research instruments were used.

\subsubsection{Structured Interviews}

Closed and Open-ended questionnaires were administered to the youth. The information sought from the youth were 
based on how they perceived HIVIAids and VCT centers, the location of VCT and about the counselors characteristics to see whether VCTs were effective in the fight against HIVIAIDS.

\subsubsection{Unstructured Interviews}

The researcher administered unstructured interviews with 8 key informants who included 4 VCT counselors and 4 health workers. These key informants were considered, as the;y were conversant with the subject under study. The counselors were the ones involved in the counseling process. The met the youth and they experienced a lot of problems in the process of counseling them hence the researcher felt that they could enrich this study greatly. Unstructured interviews were used as they provided individual opinion on the topic under study because one had room to air his views.

\subsection{Secondary data}

This was obtained from books, seminar papers and journals. These materials contained information on the role of counselors in the VCTs, the services offered in VCT centers, how the youth contained to be affected by the scourge of HIVIAIDS and the importance of VCTs in enhancing ones positive living.

\subsection{Observation}

The researcher spent one month at the VCT centers. This enabled her to observe the youth as they sought the VCT services. Most youths were seen to be restless, impatient and in need of an immediate test. However, the few willing to communicate expressed determination to change their sexual behavior. The researcher observed that when the respondents tested HIV positive, they seemed helpless and needed follow-up counseling. The researcher observed on average the amount of time it tool for the respondents to be counseled, the reaction of counselors in their work. Hence whatever the researcher observed contributed greatly into making this research better.

\subsection{Data analysis}

After the field work, quantitative data was coded and analyzed with the use of statistical package for social science (SPSS) programme. Descriptive statistics were applied to organize and summarized the data through the use of frequency distribution tables. Qualitative data consisted of the respondent's views and opinions. This was analyzed through inferential statistics where the researcher tested the truth or falsified the hypotheses. Through the use of chisquare test. Some relationships were confirmed between the different set of variables and supporting explanation given.

\section{Data Presentation and Analysis}

\subsection{Gender, Age and Marital status}

The study observed that $54 \%$ of the respondents were female while $46 \%$ were male. Majority of the youth were about 24 years of age. The study also found that among the youth $83 \%$ were single. The single status of these youth made them more vulnerable to HIVIAIDS since they wre highly sexually active. It was therefore necessary to get their views. The table below summarizes the sex, age and marital status of the respondents.

Respondent's sex, age and marital status

\begin{tabular}{|c|c|c|c|c|c|c|c|c|}
\hline \multicolumn{3}{|c|}{ Sex } & \multicolumn{4}{c|}{ Marital status } & \multicolumn{3}{c|}{ Age } \\
\hline & Male & Female & Married & Single & Divorced & $18-20$ & $21-22$ & $23-24$ \\
\hline Frequency & 40 & 46 & 14 & 71 & 1 & 20 & 19 & 45 \\
\hline Percentage & 46 & 54 & 16 & 83 & 1 & 23 & 23 & 54 \\
\hline
\end{tabular}

\subsection{Religion, Education and Employment status}

The study found that $96 \%$ the respondents were Christians while $4 \%$ were Muslims. It also showed that $69 \%$ of the respondents had attained college education and above while $24 \%$ had secondary education. It appeared that majority of the youth were well educated. However $49 \%$ of them were unemployed, $28 \%$ had permanent employment, $15 \%$ were 
casual laborer's and 9\% were involved in business. This showed that thought the youth had attained a good level of education majority were still unemployed. The table below is a summary about the religion, education level and employment status of the respondents.

\begin{tabular}{|c|c|c|c|c|c|c|c|c|c|}
\hline & \multicolumn{3}{|c|}{ Religion } & \multicolumn{3}{|c|}{ Education Level } & \multicolumn{3}{|c|}{ Employment Status } \\
\hline & Christians & Muslim & Others & $\begin{array}{c}\text { Secondary and } \\
\text { below }\end{array}$ & $\begin{array}{l}\text { College and } \\
\text { above }\end{array}$ & Unemployed & $\begin{array}{l}\text { Permanent } \\
\text { employment }\end{array}$ & Business & Casual \\
\hline Frequency & 78 & 3 & 5 & 27 & 59 & 42 & 23 & 8 & 13 \\
\hline Percentage & 90 & 4 & 6 & 31 & 69 & 49 & 28 & 9 & 15 \\
\hline
\end{tabular}

This meant that most of the youth were idle and frustrated hence very likely to be involved in alcoholism. Alcohol influence leads one to engage in irresponsible sex. This puts them at a great risk of HIVIAIDS. Joblessness among the female youth may lead them to the involved in promiscuity for their upkeep, which also put them at a risk of HIVIAIDS.

\subsection{Youth perception about HIVIAIDS}

The way an individual looks at a certain issue determines the appropriate measures he takes towards it. It was thus necessary for this study to evaluate the relative understanding about HIVIAIDS among the youth. From the study all the respondents had heard about HIVIAIDS. This meant theat they were aware that HIVIAIDS existed. It appeared that they had seen sick people with HIVIAIDS symptoms or knew people who had died of the dreaded disease.

\subsection{Sources of Information on HIVIAIDS}

A lot of campaign has been done to create awareness about HIV/Aids. It was necessary for the researcher to find out whether the youth had any information on HIVIAIDS. This was important for the youth to take the necessary measures to protect themselves. The table below summarizes the information that the youth had on HIVIAIDS.

\begin{tabular}{|c|c|c|}
\hline Sources of Information & Frequency & Percentage \\
\hline Radio & 36 & 42 \\
\hline Churches & 26 & 20 \\
\hline Parents & 8 & 9 \\
\hline Newspapers & 8 & 9 \\
\hline Seminars & 4 & 5 \\
\hline Billboards & 3 & 4 \\
\hline Posters & 1 & 1 \\
\hline
\end{tabular}

The study showed that $42 \%$ of the respondents had information on HIVIAIDS from the Radio $22 \%$ from churches, $17 \%$ from the parents, $9 \%$ from the newspapers, $5 \%$ from seminars, $4 \%$ from billboards and $1 \%$ from posters.

The radio is a major source of information on HIVIAIDS as it is affordable. Both the poor and the rich have access to the radio due to its low cost. The radio transmits information in different languages hence it can reach most of the people at whatever level. The religious groups have also accepted that HIVIAIDS is a reality and are creating awareness, as the study observed that $20 \%$ of the information was from the churches.

\section{Conclusion}

This section provides a summary of key findings and recommendations arrived at based on the expected situation as understood from the literature review and the actual research finding. The key objective of this study was to examine the effectiveness of VCTs in the fight against HIVIAIDS. The youth had heard about HIVIAIDs and the came to know about this disease from the radio, newspapers, posters, billboards, churches and from parents. The youth were also aware about the seriousness of the disease that it's a national disaster, that it kills and its real.

However, the study found many of those interviewed had been in sexual relationships ranging from 1-14 partners. Yet they still believed that they could not contract HIVIAIDS because they were faithful and trusted their partners. It was therefore clear by the fact that the study found only a small percentage of those interviewed who were sexually active used condom as a measure to protect themselves from HIVIAIDS hence they continued to expose themselves to the risk 
of HIVIAIDS by having unprotected sex.

Although the study found out that many of the youth knew about HIVIAIDs and VCT and they had gone for VCT services. Most youth were afraid to cope with bad news of being HIV positive. Peer pressure played a vital role in the youth not seeking VCT site three times but had never tested for HIV, yet this same youth admitted to be sexually active.

\subsection{VCT Process}

Counseling in the VCT centers may not be easy for the counselors play more than one role as they are also nurses at the Health centers. The study observed that the youth indicated that they did not expect the counseling process to be long as majority spent between 45 minutes to 2 hours from the time they arrived at the VCT centre to the time they left. Others got discouraged by the long queues and had to go away. Others having been prepared to be tested on a particular day were given an appointment to come on another day, which could be discouraging because they had set their mind to be tested.

The counselors interviewed after attending the youth indicated that the youth were impatient, nervous and only wanted an immediate test. The process of counseling to them was a waste of time. The counselors also faced the problem of communication; some client neither knew Kiswahili nor English. The researcher witnessed a case of three Sudanese, who communicating with them was a major problem; no meaningful contact would be established with them. Post-test clubs hardly exist; hence it becomes difficult where the youth can be referred to once they have tested HIVIAids positive, bearing in mind that the study found the youth have poor copying abilities with bad news. Such test clubs would be vital for support.

\subsection{Counselor characteristics and their influence on HIV/AIDS testing}

The youth interviewed showed that the counselors in the VCT rooms were as old as their parents. When this information is passed on to the other youth who have not had HIVIAIDS test, they get discouraged. The youth do not want their parents to know about their sexual life. It is no wonder that most youths at the VCT centers did not open up; they blocked further probing, and shied off when the issue of their sexuality came up as claimed by the counselors. The counselors felt inadequate when handling the youth issues. They claimed to find it difficult to question the youth on sexual matters.

Most youths used the sheng language, which the counselors found difficult to understand, and at times they could be given wrong information. The youth preferred other youths like them as they counselors. Many indicated that they liked the same sex counselors. Although the youth indicated that the counselors are competent in their work, it seemed clear from the study that they would like them to undergo further training. The counselors who unanimously agreed that further training would enable them deal with the youth issues also confirm this.

\subsection{Location of VCT Centers}

The VCT sites need to be checked in order to attract the youth. The study found out the most VCT centers were located within the health centers. This prevented the youth form attending them. They viewed those watching them as being judgmental on the sexual behavior. The VCT at Ruiru is located next to the pediatrician's room hence with the wailing of the babies, the environment is not conducive at all for good counseling to take place. On the other hand the VCT at Thika is located behind the main hospital and with no exit door the clients going to the VCT have to pass through the main hospital.

At the same time the current VCT centers are not youth friendly, they do not have facilities for the youth like games etc. Yet these facilities would be attractive because as the youth come from them they can undergo the HIVIAIDS test. However, the study found out that youth did not fail to go for VCT because of the distance as having a test is a matter of interest, but the fact that most youths were unemployed as found out in the study they may not have money for transport and payment at the VCT centers.

\section{References}

Aids care Vol 1 No 2 (1989); Hiv counseling, problems and opportunities in defining the new agenda for the 1990's"

Aids care vol7 No 2 (1995); HIV counseling and testing; research policy issues."

Aids care (1997) vol 9 No 1: Participatory evaluation of counseling, medical and social services of the Aids support organization Taso in Ugand. "A joint study by the population council, Horizons project and FHI Kenya Aids counseling and testing care and support 
services in Nairobi Kenya".

Alcock et al (1987); "A text book of social psychology" Prentice Hall Auyn A parent guide (1999); "Talking sexual health."

Blammer D.H (1991); "Towards a unified theory of HIVIAIDS counseling, international journal for the advancement of counseling', Klumer Academic publishers.

Bisualo (1994);"perception of appropriate HIVIAIDS counselor in Arush and Kilimanjaro region of Tanzania.

Bisualo P.M (1996):"on HIV counseling, HIV an introduction to guidance and counseling - Der-es-salaam University press".

Boswel (2002);"VCT and youth people, A summary overview."

Catania, JA Kegeles and Coates T (1990) - "Towards understanding of risk behavior" An aids risk reduction model New York, pergamon press.

Cattle (1973); "Beginning counseling Practicum" Guinea and Stratton.

Dilton et al Jan (2001): "VCT services, centers for disease control and prevention, national center for HIVISTD and T.B prevention".

East African standard - Wed July 9: (2003)

FHI May (2002):"A guide to establishing VCT services for HIV."

FHI June (2002): "VCT and young people, "A summary overview"

FHI (2002):" Youth lens on reproductive health and HIVIAIDS."

Fishbein summarizing Becken (1984): In developing effective behavior change interventions."

George Ritzen (1983): " Contemporary Sociological theory ," Alfred A. Knopf".

Health policy and planning (2000): "An orientation package for healthcare workers in VCT services in Kenya.

Http/www/unfpa. Org/Aids/Prevention/HIV pre 3b. Ltm.

Horizons report Sep(2002) Nairobi. "The challenge and meaning of VCT counselor."

Kamende et al (1999); "Service provider's perspective on preparedness in providing youth specific counseling."

Kemri, UON(1999); consultative technical meeting on VCT. Continuum of care."

Kemri (2001); "HIV and the youth "can we avoid the catastrophe, why does adolescence increase vulnerability to HIVIAIDS.

Millstein et al(1993); "Promoting the health of adolescents; new direction for the $21^{\text {st }}$ century."

Nascop/Jhpiegor nor (2001); An orientation package for Healthcare workers on VCT services in Kenya.

Nzioka C.B.K may (1994)' "The social Construction and management of HIVIAids menace effectively". By circuit city limited.

Plant (1993); "Aids, drugs and prostitution " Routledge.

Population Council and Family Health International (1999) . "HIVIAids C.TC.S services in Nairobi Kenya.

Planned parenthood federation (2001); "A social mobilization programme to educate young people on prevention."

Spencer et al (1994) ; "Aids what every student needs to know," Brace College Publishers"

Tonks doughous (1996); " Teaching Aids " Routledge New York."

Ubal arselem (1990) : "Counselling Hints" clarerianum press".

UNAids May (2000)"'Technical update on VCT."

WHO (1993); " Counseling skills; Training in Adolescent, sexuality and reproductive health."

WHO (1998): Improving Adolescent Health and development."

WHO(1999);" UNAids, HIVIAIDS and STD'S initiative.

www.unaids.org

www. Usaid(gov) 